OPEN ACCESS

Edited by:

Zhiyou Yuan,

Northwest A\&F University, China

Reviewed by:

Juliana S. Medeiros, Holden Arboretum, United States

Raffaella Balestrini,

Institute for Sustainable Plant

Protection (IPSP-CNR), Italy

*Correspondence:

Xue-Li He

x/h3615@126.com

Specialty section:

This article was submitted to

Plant Abiotic Stress,

a section of the journal

Frontiers in Plant Science

Received: 30 October 2018

Accepted: 26 June 2019

Published: 11 July 2019

Citation:

Li X, He X-L, Zhou Y, Hou Y-T and

Zuo Y-L (2019) Effects of Dark

Septate Endophytes on the Performance of Hedysarum scoparium Under Water Deficit Stress. Front. Plant Sci. 10:903. doi: 10.3389/fpls.2019.00903

\section{Effects of Dark Septate Endophytes on the Performance of Hedysarum scoparium Under Water Deficit Stress}

\author{
Xia Li', Xue-Li He ${ }^{1 *}$, Yong Zhou'2, Yi-Ting Hou ${ }^{1}$ and Yi-Ling Zuo ${ }^{1}$ \\ ${ }^{1}$ College of Life Science, Hebei University, Baoding, China, ${ }^{2}$ College of Landscape Architecture and Tourism, Hebei \\ Agricultural University, Baoding, China
}

Hedysarum scoparium, a species characterized by rapid growth and high drought resistance, has been used widely for vegetative restoration of arid regions in Northwest China that are prone to desertification. Desert soil is typically deficient in available water and the alleviation of drought stress to host plants by endophytes could be an efficient strategy to increase the success of desert restoration. With the objective to seek more beneficial symbionts that can be used in the revegetation strategies, we addressed the question whether $H$. scoparium can benefit from inoculation by dark septate endophytes (DSEs) isolated from other desert plants. We investigated the influences of four non-host DSE strains (Phialophora sp., Knufia sp., Leptosphaeria sp., and Embellisia chlamydospora) isolated from other desert plants on the performance of $H$. scoparium under different soil water conditions. Differences in plant performance, such as plant growth, antioxidant enzyme activities, carbon, nitrogen, and phosphorous concentration under all the treatments, were examined. Four DSE strains could colonize the roots of $H$. scoparium successfully, and they established a positive symbiosis with the host plants depending on DSE species and water availability. The greatest benefits of DSE inoculation occurred in water stress treatment. Specifically, Phialophora sp. and Leptosphaeria sp. improved the root biomass, total biomass, nutrient concentration, and antioxidant enzyme activities of host plants under water deficit conditions. These data contribute to the understanding of the ecological function of DSE fungi in drylands.

Keywords: Hedysarum scoparium, dark septate endophytes, water deficit stress, non-host endophytes, inoculation

\section{INTRODUCTION}

Approximately $27 \%$ of the land area in China is exposed to desertification, causing critical ecological and environmental problems, especially in Northwest China (Tang et al., 2016). The Chinese government has implemented a variety of solutions, including afforestation projects, to reduce the effect of desertification (Su et al., 2007; Fan et al., 2016). Over the past few decades, 
restoration of deserts using xerophyte shrubs is viewed as a common and effective method in many arid regions (Zhu and Chen, 1994; Wang et al., 2012; Deng et al., 2015). These plants have evolved various mechanisms, including altered morphological and physiological properties, to cope with drought stress (Deng et al., 2015; Li et al., 2017). Plants in natural habitats often harbor ubiquitous fungal endophytes, some of which are drought-tolerant and can stimulate plant growth in arid ecosystems (Ren et al., 2011; González-Teuber et al., 2018; Xie et al., 2018). Mitigating drought stress in host plants by endophytes may be an efficient strategy to improve the restoration rate of desert soils, which are typically deficient in available water (Gong et al., 2015; Shi et al., 2015; GonzálezTeuber et al., 2018).

Most desert plants associate with a wide diversity of root endophytic fungi, including dark septate endophytes (DSEs) (Barrow, 2003; Porras-Alfaro et al., 2008; González-Teuber et al., 2017). These endophytes are characterized by melanized septate hyphae and microsclerotia and are found in the roots of more than 600 plant species (Jumpponen and Trappe, 1998). DSE are abundant root colonists especially in plants growing under extreme conditions such as arid environments (Jumpponen and Trappe, 1998; Barrow and Osuna, 2002). Many researchers have investigated and isolated a variety of DSE from grasses, shrubs, and trees in arid areas (Lugo et al., 2009, 2015; Knapp et al., 2012, 2015; Li et al., 2015, 2018; Xie et al., 2017). For instance, Lugo et al. (2015) investigated DSE in 42 plants from an arid region in Argentina and showed that DSE were frequently present in the roots. In Northwest China, DSE were also observed and identified in the roots of multiple desert shrubs, such as Ammopiptanthus mongolicus, Hedysarum scoparium, and Gymnocarpos przewalskii (Li et al., 2015, 2018; Xie et al., 2017). For example, in our previous survey conducted in seven arid and semi-arid locations in Northwest China, we showed that $H$. scoparium was highly colonized by DSE and we isolated nine DSE species from their roots (Xie et al., 2017). However, our understanding of DSE functions in relation to plants is still limited (Barrow, 2003).

Although not all DSE-plant relationships are beneficial, there is a strong evidence to suggest that DSE may positively influence plant resistance to drought by increasing plant growth, water and nutrient absorption, and/or facilitating plant resistance to oxidation stress (Perez-Naranjo, 2009; Santos et al., 2017). In field experiments, Barrow (2003) investigated the DSE of native grasses in arid southwestern United States rangelands. The author proposed that DSE may form a continuous integrated network that enhances nutrient and water transport in roots. DSE are readily isolated and cultured in vitro, which has facilitated the studies on the effects of DSE on host plants under water stress in controlled culture conditions. In pot experiments, desert plants Agropyron cristatum and Psathyrostachys juncea inoculated with DSE developed a higher shoot biomass and carbon content compared with non-inoculated plants under drought conditions (Perez-Naranjo, 2009). Similarly, Santos et al. (2017) conducted an inoculation experiment to study the influence of DSE isolates on rice under water deficit induced with polyethylene glycol 6000. Their results showed that DSE increase the growth and decrease the oxidative stress in rice plants. However, this positive effect occurred only in specific water stress conditions.

Hedysarum scoparium, a species characterized with rapid growth and high drought resistance, is a pioneer desert shrub that has been widely used for prevention of desertification and vegetative restoration in arid and semiarid regions of China ( $\mathrm{Hu}$ et al., 2009). In a pot experiment conducted in our study, DSE isolated from healthy roots of $H$. scoparium, colonized the host roots and increased the shoot and root biomass of $H$. scoparium plants (Supplementary Figure 1). With the objective to seek more beneficial symbionts that can be used in revegetation strategies, we investigated whether $H$. scoparium can benefit from DSE isolated from other desert plants. Four DSE isolated from the roots of $G$. przewalskii, a species with similar growth habit and ecological distribution to that of $H$. scoparium, were selected for the inoculation experiment. These fungi colonized the roots of other desert plants with no apparent disease symptoms and enhanced plant growth under drought conditions ( $\mathrm{Li}$ et al., 2018). In this study, we aimed to evaluate the effects of nonhost DSE inoculation on $H$. scoparium plants growing in drought sandy soil under greenhouse conditions. We focused on plant growth, nutrient content, and activity of antioxidant enzymes to address the following questions: (1) Do DSE from other plants colonize the roots of $H$. scoparium under well-watered and water deficit conditions? (2) If yes, can these non-host DSE improve the growth and physiological performance of $H$. scoparium plants? (3) Does water availability affect the symbiosis-dependent benefits? (4) How non-host DSE help H. scoparium plants to overcome water deficit stress?

\section{MATERIALS AND METHODS}

\section{Fungal Isolates and Plant Materials}

Four DSE fungi isolated from the roots of G. przewalskii, which grows naturally in extreme arid deserts of Northwest China, were used in this experiment. Their species identification was confirmed previously through internal transcribed spacer (ITS) phylogeny (Li et al., 2018). All the fungal isolates belonged to different species and they included: Phialophora sp., Knufia sp., Leptosphaeria sp., and Embellisia chlamydospora. These fungi are deposited in the culture collection of the Laboratory of Plant Ecology, Hebei University, China, and their ITS sequences are available from GenBank under accession numbers MF036001 for Phialophora sp., MF036003 for Knufia sp., MF036004 for Leptosphaeria sp., and MF036005 for E. chlamydospora.

Hedysarum scoparium was chosen as a host plant in this study mostly for its important role in vegetation restoration and known high DSE colonization frequency (Xie et al., 2017). The seeds of H. scoparium were collected from natural populations in Gansu Province, Northwest China, and stored at $4^{\circ} \mathrm{C}$.

\section{Experimental Design}

The experiment was conducted in a growth chamber in a completely randomized factorial design (5 inoculation treatments $\times 2$ water treatments) with five replicates. The inoculation treatments included inoculation with Phialophora 
sp., Knufia sp., Leptosphaeria sp., and E. chlamydospora and a non-inoculated control. The water treatments were well-watered and water deficit stress. A total of 50 pots were prepared.

The seeds of $H$. scoparium were surface-sterilized by dipping in $70 \%$ ethanol for $3 \mathrm{~min}$ and then in $2.5 \%$ sodium hypochlorite for 10 min with agitation. The sterilized seeds were gently washed by sterile water several times and then aseptically planted onto water agar medium (containing $10 \mathrm{~g} / \mathrm{L}$ agar) in Petri dishes for germination at $27^{\circ} \mathrm{C}$. Following pregermination, each seedling was transferred into sterile pot ( $8 \mathrm{~cm}$ diameter, $24 \mathrm{~cm}$ height) containing $500 \mathrm{~g}$ sand collected from the natural habitats of H. scoparium and autoclaved for $120 \mathrm{~min}$ at $121^{\circ} \mathrm{C}$. The basic physicochemical characteristics of the sand were as follows: organic matter $23.17 \mathrm{mg} / \mathrm{g}$, available nitrogen $21.63 \mathrm{mg} / \mathrm{kg}$, and available phosphorus $1.53 \mathrm{mg} / \mathrm{kg}$. One month later, half of the seedlings were maintained under well-watered conditions throughout the entire experiment (70\% field water capacity), and the other half were exposed to water deficit stress (30\% field water capacity). Water loss was daily supplemented with sterile distilled water to keep the desired field capacity by regular weighing. The water content for water deficit treatment was chosen according to the median value in the natural habitat of $H$. scoparium in Northwest China (Xie, 2017).

Fungal inocula were prepared by aseptically growing DSE isolates in Petri dishes with potato dextrose agar culture medium. For DSE inoculation, two $5 \mathrm{~mm}$ plugs excised from an edge of an actively growing colony on culture medium were inoculated at a $1 \mathrm{~cm}$ range close to the roots of $H$. scoparium seedlings. The non-inoculated controls were inoculated with plugs excised from the sterile medium without fungus. All the inoculation processes were carried out on a clean bench, and all the pots were kept in a growth chamber with a $14 \mathrm{~h} / 10 \mathrm{~h}$ photoperiod, temperature of $27^{\circ} \mathrm{C} / 22^{\circ} \mathrm{C}$ (day/night), and $60 \%$ mean air relative humidity. The duration of the stress experiment was 4 months.

\section{Harvest of Hedysarum scoparium Seedlings}

At the end of the experiment, the shoots and roots from each plant were separately harvested, and the roots were gently washed with tap water to remove the sand. Subsamples of fresh roots and shoots were set aside for assessing DSE colonization status and antioxidant enzyme activity, respectively, as described below. The remaining part of shoots and roots were weighed before drying in an oven at $70^{\circ} \mathrm{C}$ for $48 \mathrm{~h}$ and the water content was measured. The biomass production of plants was the sum of the dry weights of these two parts. After that the dried shoot and root materials were ground into a powder to measure the concentrations of carbon $(\mathrm{C})$, nitrogen $(\mathrm{N})$, and phosphorus $(\mathrm{P})$.

\section{Microscopic Observation of Root Colonization}

Root colonization by DSE isolates was evaluated using the method described by Phillips and Hayman (1970). The sampled roots were cleared with $10 \% \mathrm{KOH}$ in a water bath at $100^{\circ} \mathrm{C}$ for $60 \mathrm{~min}$ and then stained with $0.5 \%(\mathrm{w} / \mathrm{v})$ acid fuchsin at $90^{\circ} \mathrm{C}$ for $20 \mathrm{~min}$. Overall, 20 randomly selected $0.5 \mathrm{~cm}$ long root segments per sample were placed on slides and observed under an optical microscope.

\section{Determination of Antioxidant Enzyme Activity}

To determine the activity of different antioxidant enzymes, fresh leaf samples from each plant were homogenized in $5 \mathrm{~mL}$ of $50 \mathrm{mM}$ potassium phosphate buffer ( $\mathrm{pH} 7.8)$, which contained chilled $0.2 \mathrm{mM}$ EDTA and 2\% (w/v) polyvinylpyrrolidone kept in ice bath. Prechilled mortar and pestle were used for grinding. The homogenate was centrifuged at $15,294 \times g$ and $4^{\circ} \mathrm{C}$ for $30 \mathrm{~min}$. The supernatant was decanted and used for analysis of enzymes.

The superoxide dismutase (SOD) activity was determined using the photochemical method described by Elavarthi and Martin (2010) by recording the decrease in the absorbance of nitro blue tetrazolium complex due to its reduction by the enzyme. One unit of SOD was equivalent to the quantity of enzyme needed to inhibit the reduction rate of NBT by $50 \%$ at a wavelength of $560 \mathrm{~nm}$. The catalase (CAT) activity was determined by measuring the consumption of $\mathrm{H}_{2} \mathrm{O}_{2}$ at $240 \mathrm{~nm}$ wavelength for $1 \mathrm{~min}$. The reaction mixture consisted of $25 \mathrm{mM}$ potassium phosphate buffer ( $\mathrm{pH} 7.0$ ), $10 \mathrm{mM} \mathrm{H}_{2} \mathrm{O}_{2}$, and enzyme extract (Cakmak and Marschner, 1992).

\section{Carbon, Nitrogen, and Phosphorus Concentrations}

The $\mathrm{C}$ and $\mathrm{N}$ concentrations in the shoots and roots were directly determined using the dry combustion method with an elemental analyzer (Vario EL/micro cube; Elementar, Hanau, Germany). For determination of $\mathrm{P}$ concentrations, dried ground shoot and root samples were digested in $\mathrm{HNO}_{3}$, followed by a microwaveaccelerated reaction in a Microwave-Accelerated Digestion System (MARS; CEM, Corp., Matthews, NC, United States). The $\mathrm{P}$ concentrations were measured by the molybdenum-antimony colorimetric method (Bao, 2000).

\section{Statistical Analysis}

All statistical analyses were performed with SPSS software (Version 21; SPSS, Chicago, IL, United States). A twoway analysis of variance was used to analyze the effects of DSE inoculation, water treatment, and their interaction on plant biomass, leaf antioxidant enzyme activity, and element concentrations in the roots and shoots. All data were tested for normality and homogeneity of variance before statistical analyses. The differences between the means among different treatments were compared using Duncan's multiple-range tests at $P<0.05$.

\section{RESULTS}

\section{DSE Root Colonization}

After harvesting, no DSE structures were detected in the roots of control plants regardless of water treatment, while the presence of DSE hyphae and microsclerotia was confirmed in stained root segments of inoculated plants (Supplementary Figure 2). 
TABLE 1 | Analysis of variance for the effects of DSE inoculation and water stress treatment on biomass production of Hedysarum scoparium.

\begin{tabular}{|c|c|c|c|c|c|c|}
\hline & \multicolumn{2}{|c|}{ Shoot biomass (g) } & \multicolumn{2}{|c|}{ Root biomass (g) } & \multicolumn{2}{|c|}{ Total biomass (g) } \\
\hline & $\boldsymbol{F}$ & $P$ & $\boldsymbol{F}$ & $P$ & $\boldsymbol{F}$ & $P$ \\
\hline DSE & 11.6 & $<0.001$ & 18.0 & $<0.001$ & 17.2 & $<0.001$ \\
\hline $\begin{array}{l}\text { Water } \\
\text { stress }\end{array}$ & 406.7 & $<0.001$ & 300.6 & $<0.001$ & 420.7 & $<0.001$ \\
\hline $\begin{array}{l}\text { DSE } \times \text { Water } \\
\text { stress }\end{array}$ & r 1.8 & 0.156 & 3.8 & 0.011 & 3.2 & 0.023 \\
\hline
\end{tabular}

\section{Plant Biomass Production}

The shoot biomass of $H$. scoparium was affected significantly by the DSE inoculation regardless of the water regime (Table 1). Specifically, the inoculation of Phialophora sp. and Leptosphaeria sp. resulted in significant increases in shoot biomass (by 9.0 and $17.9 \%$, respectively) compared to control plants (Figure 1).

The interactions of DSE inoculation and water treatment were significant for both the root and total biomass of $H$. scoparium seedlings (Table 1). Under well-watered conditions, inoculation with Leptosphaeria sp. led to a significantly greater root and total biomass (40.0 and $35.1 \%$, respectively) compared
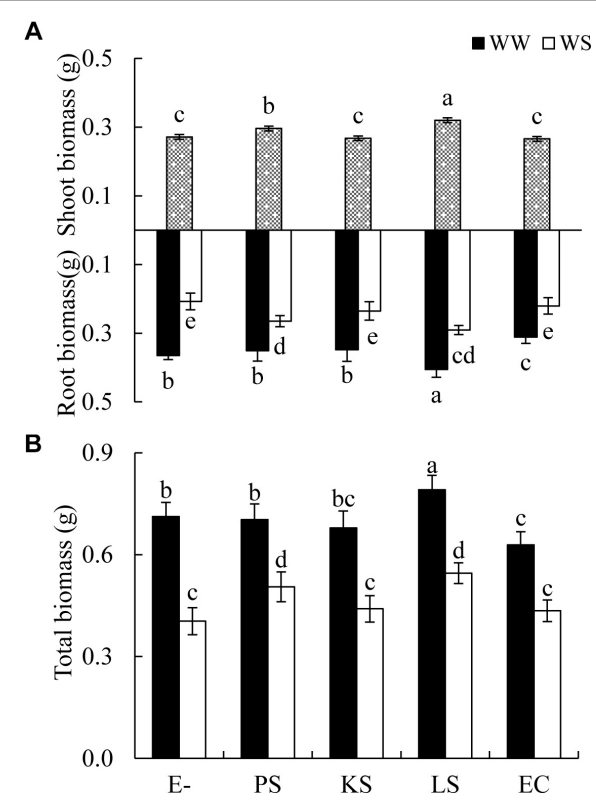

FIGURE 1 | Effects of dark septate endophyte (DSE) inoculation and water treatment on the biomass production of Hedysarum scoparium. (A) Shoot and root biomass of Hedysarum scoparium. (B) Total biomass of Hedysarum scoparium. The error bars represent the standard error (SE). Different letters above the error bars indicate significant difference at $P<0.05$ by Duncan's multiple-range tests. Since DSE $\times$ water treatment interactions were not significant for shoot biomass, means for the main factor (DSE) were presented. E- indicates non-inoculated plants. PS, KS, LS, and EC indicate plants inoculated with Phialophora sp., Knufia sp., Leptosphaeria sp., and Embellisia chlamydospora, respectively. WW and WS indicate well-watered and water stress treatment. with those of the control plants, whereas the inoculation with E. chlamydospora resulted in a 14.8 and $11.7 \%$ decrease in both parameters, respectively (Figure 1). Under water stress conditions, Phialophora sp. and Leptosphaeria sp. inoculations caused a significantly greater root (27.5 and $40.0 \%)$ and total biomass (25.1 and 35.1\%) compared with those observed in control plants, respectively. There was no significant difference in the root and total biomass production among plants inoculated with Knufia sp. and E. chlamydospora and the control (Figure 1).

\section{Antioxidant Enzyme Activities in Leaves of Hedysarum scoparium}

The interaction between DSE inoculation and water treatment showed significant effects on the antioxidant enzyme activities in leaves of H. scoparium (Table 2). In general, all the tested DSE caused remarkable increases in the activities of SOD and CAT under water stress conditions, which was closely related to the drought tolerance of $H$. scoparium (Figure 2). Plants inoculated with Phialophora sp., Knufia sp. and Leptosphaeria sp. showed significantly higher values of SOD $(19.1,26.4$, and $36.4 \%$ ) and CAT (43.2, 27.2, and $31.1 \%$, respectively) activities compared with control plants under water stress conditions. However, under well-watered conditions, there were no significant differences in either SOD or CAT activity between DSE inoculated plants and control plants. E. chlamydospora inoculation had no significant effects on host plants compared with control plants under both water regimes (Figure 2).

\section{Element Concentration in Plant Tissues}

There was a significant interaction between the DSE inoculation and water treatment on the shoot $\mathrm{C}$ concentration of $H$. scoparium (Table 2). The shoot $\mathrm{C}$ concentration was significantly lower $(2.5 \%)$ in E. chlamydospora-inoculated H. scoparium plants than in the control plants under well-watered conditions, but there was no significant effect of DSE inoculation on the shoot $\mathrm{C}$ content in host plants in all the other treatments (Figure 3A). The $\mathrm{N}$ concentration in the shoots of $H$. scoparium was affected significantly by the DSE inoculation, water treatment, and their interaction (Table 2). Under water stress conditions, inoculation with Phialophora sp. and Leptosphaeria sp. resulted in a significant increase in the $\mathrm{N}$ concentration in the shoots of $H$. scoparium by 22.9 and $20.2 \%$, respectively, when compared with control plants. Under well-watered conditions, Leptosphaeria sp. induced a significant increase in the shoot $\mathrm{N}$ concentration (12.3\%), while E. chlamydospora showed an opposite effect, with about $87.7 \%$ of control plants (Figure 3B). DSE inoculation did not affect the root $\mathrm{C}, \mathrm{N}$, and $\mathrm{P}$ concentrations and shoot $\mathrm{P}$ concentration of $H$. scoparium seedlings under all the treatments (Figure 3 and Table 2).

\section{DISCUSSION}

As important root endophytes, DSE have been reported to have positive ecological roles in plant growth and nutrient uptake (Wu et al., 2010; Newsham, 2011; Surono and Narisawa, 2017; Vergara et al., 2018). They also provide increased plant resistance 


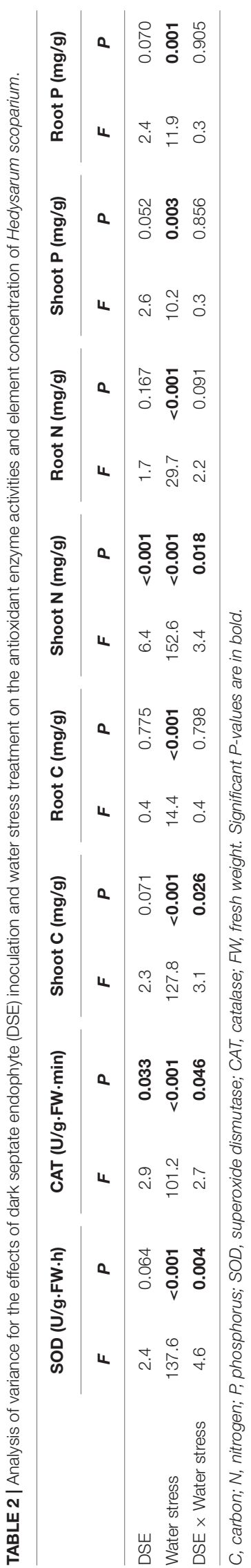

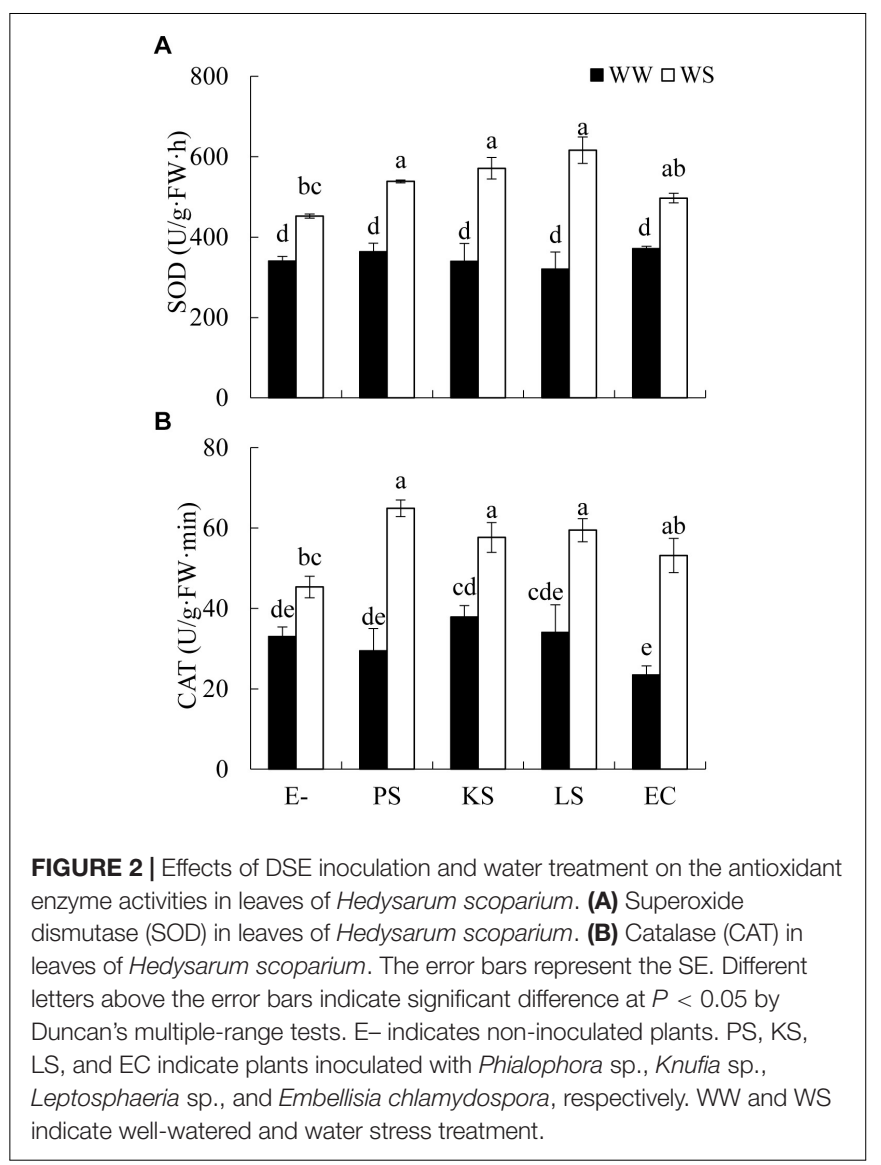

to a wide range of environmental stressors (Andrade-Linares et al., 2011; Likar and Regvar, 2013; Su et al., 2013; Berthelot et al., 2017; Santos et al., 2017; Zhang et al., 2017; Jin et al., 2018). However, little is known about the relationship of nonhost DSE and host plants, especially when water availability is considered (Zhang et al., 2017). In the studies using crops and plants growing in heavy metal-contaminated soils, DSE fungi, which have been considered non-host colonizers, showed the potential to improve plant growth (Li et al., 2011; Khastini et al., 2012; Berthelot et al., 2016, 2017; Wang et al., 2016). For example, Gaeumannomyces cylindrosporus isolated from plants naturally growing in an ancient $\mathrm{Pb}-\mathrm{Zn}$ slag heap were reported to enhance the growth of maize under Cd stress (Ban et al., 2017). Similarly, the four DSE in this study isolated from G. przewalskii were able to colonize the roots of $H$. scoparium plants under both well-watered and water deficit conditions. Similarly, Zhang et al. (2017) reported that Exophiala pisciphila isolated from maize could colonize the roots of Sorghum bicolor. Our results indicated that DSE isolated from desert plants may be used in other plants. Moreover, they exhibited positive effects on shoot $\mathrm{C}$ and $\mathrm{N}$ content and biomass production of $H$. scoparium plants; however, these effects were straindependent. This observation corroborates previous reports that state that DSE fungal species may be one of the factors that influence the symbiotic relationship (Wilcox and Wang, 1987; Mandyam and Jumpponen, 2005; Newsham, 2011). In addition, 

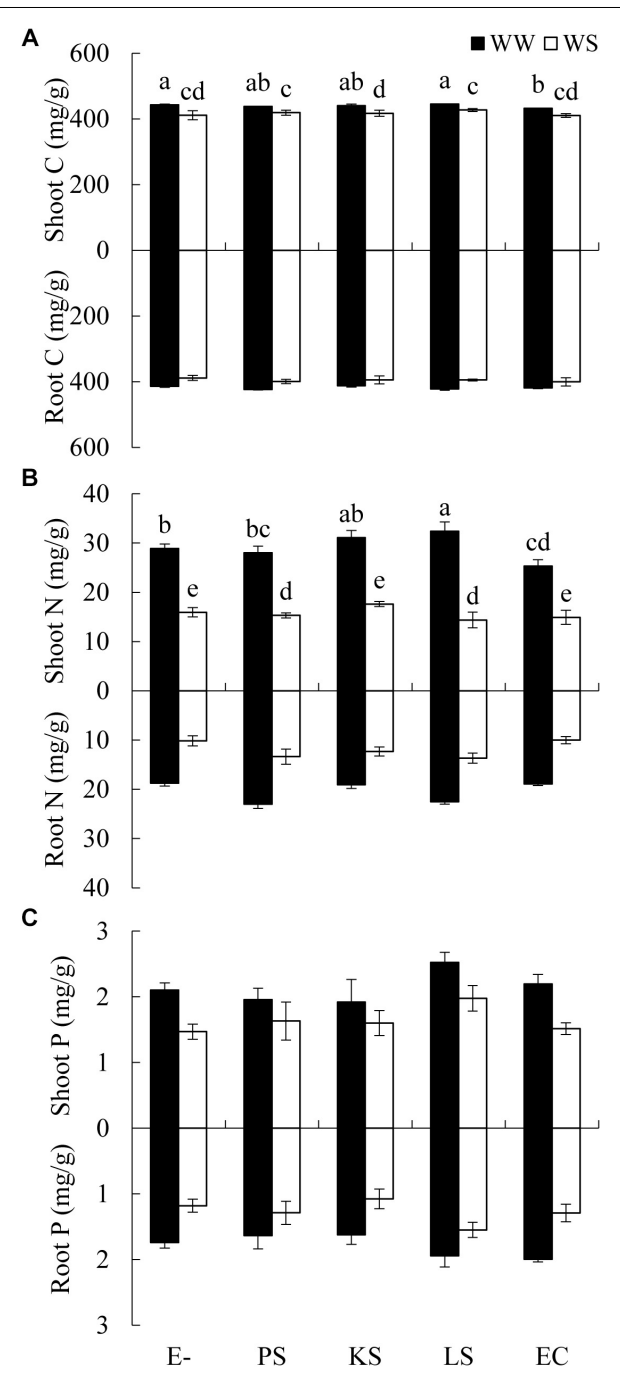

FIGURE 3 | Effects of DSE inoculation and water treatment on the elemental concentration of Hedysarum scoparium. (A) Shoot and root carbon concentration (C) of Hedysarum scoparium. (B) Shoot and root nitrogen concentration (N) of Hedysarum scoparium. (C) Shoot and root phosphorus concentration $(P)$ of Hedysarum scoparium. The error bars represent the SE. Different letters above the error bars indicate significant difference at $P<0.05$ by Duncan's multiple-range tests. The estimated means were presented when interactions were not significant. E- indicates non-inoculated plants. PS, KS, LS, and EC indicate plants inoculated with Phialophora sp., Knufia sp., Leptosphaeria sp., and Embellisia chlamydospora, respectively. WW and WS indicate well-watered and water stress treatment. in all the plants inoculated with DSE. The biomass production and shoot $\mathrm{C}$ and $\mathrm{N}$ content of plants inoculated with Phialophora sp. and Leptosphaeria sp. was increased compared with that of the control, whereas the inoculation of $H$. scoparium plants with E. chlamydospora negatively affected plant growth under wellwatered conditions, but caused no significant decline in plant growth when exposed to water stress. This indicates that the interaction between DSE and $H$. scoparium becomes positive under water stress. Our results agree with previous studies in other crops, which have shown that the benefits of plantendophyte associations seem to be stronger under soil water stress conditions (Zhang et al., 2017). For H. scoparium plants, benefits of symbiosis under water stress may be advantageous to the plant growth in their natural drought habitats.

The ability of DSE fungi to promote plant growth under water stress conditions may be related to the increased $\mathrm{C}$ and $\mathrm{N}$ absorption, as well as to the enhanced activities of antioxidant enzymes. Vergara et al. (2018) have reported that increased $\mathrm{N}$ absorption by tomato plants was in response to inoculation with DSE isolates-inoculated plants exhibited higher dry weight than non-inoculated plants when supplied with organic $\mathrm{N}$. Similarly, in our study, Phialophora sp. and Leptosphaeria sp. may have facilitated the absorption of $\mathrm{C}$ and $\mathrm{N}$ in the shoots of H. scoparium. This might be due to the ability of DSE fungi to mineralize organic compounds containing $\mathrm{C}, \mathrm{N}$, and $\mathrm{P}$, thereby making them available to plants (Della Monica et al., 2015; Surono and Narisawa, 2017). For example, Phialocephala fortinii, a plant growth promoter in many studies, was reported to have the ability to degrade polymeric forms of $\mathrm{C}, \mathrm{N}$, and $\mathrm{P}$ such as cellulose, starch and protein (Caldwell et al., 2000; Surono and Narisawa, 2017). The increased SOD and CAT activity is another possible mechanism of increased plant growth. Water stress usually exerts negative effects on organisms and causes cellular oxidative damage (Bartels and Sunkar, 2005). SOD and CAT are the primary enzymes involved in the antioxidant system of plants (Khan et al., 2018; Saleem et al., 2018). In the present study, plants inoculated with Phialophora sp., Knufia sp., and Leptosphaeria sp. contained significantly higher concentrations of SOD and CAT compared with control plants under water deficit conditions. These findings can be related with the work by Santos et al. (2017), who found that DSE increased the tolerance of rice plants to water stress through altered antioxidant enzyme activity. However, the mechanisms leading to an increase in the growth of plants inoculated with DSE fungi warrants further research.

\section{CONCLUSION}

We found that non-host DSE could colonize the roots of $H$. scoparium and benefit the plant growth, through combined mechanisms of increased nutrient absorption and enhanced antioxidant systems, under water deficit conditions. Our results complement previous insight that endophytes can promote drought resistance in plants and highlight the importance of using DSE in desert plants in water-stressed conditions (Kivlin et al., 2013; Shi et al., 2015; Zhang et al., 2017; 
González-Teuber et al., 2018; Xie et al., 2018). As H. scoparium plays important roles in vegetative restoration, the DSE$H$. scoparium association has the potential for further testing in the field to determine its ability to suppress desertification in arid regions of Northwest China.

\section{AUTHOR CONTRIBUTIONS}

$\mathrm{XL}$ and $\mathrm{X}-\mathrm{LH}$ conceived and designed the experiments and wrote the manuscript. XL, YZ, Y-TH, and Y-LZ performed the experiments. XL and $\mathrm{YZ}$ analyzed the data.

\section{REFERENCES}

Andrade-Linares, D. R., Grosch, R., Restrepo, S., Krumbein, A., and Franken, P. (2011). Effects of dark septate endophytes on tomato plant performance. Mycorrhiza 21, 413-422. doi: 10.1007/s00572-010-0351-1

Ban, Y., Xu, Z., Yang, Y., Zhang, H., Chen, H., and Tang, M. (2017). Effect of dark septate endophytic fungus Gaeumannomyces cylindrosporus on plant growth, photosynthesis and $\mathrm{Pb}$ tolerance of maize (Zea mays L.). Pedosphere 27, 283-292. doi: 10.1016/s1002-0160(17)60316-3

Bao, S. D. (2000). Agrochemical Analysis of Soil. Beijing: Chinese Agricultural Press.

Barrow, J. R. (2003). Atypical morphology of dark septate fungal root endophytes of Bouteloua in arid southwestern USA rangelands. Mycorrhiza 13, 239-247. doi: 10.1007/s00572-003-0222-0

Barrow, J. R., and Osuna, P. (2002). Phosphorus solubilization and uptake by dark septate fungi in fourwing saltbush, Atriplex canescens (Pursh) Nutt. J. Arid. Environ. 51, 449-459. doi: 10.1006/jare.2001.0925

Bartels, D., and Sunkar, R. (2005). Drought and salt tolerance in plants. Crit. Rev. Plant Sci. 24, 23-58. doi: 10.1080/07352680590910410

Berthelot, C., Blaudez, D., and Leyval, C. (2017). Differential growth promotion of poplar and birch inoculated with three dark septate endophytes in two trace element-contaminated soils. Int. J. Phytoremediat. 19, 1118-1125. doi: 10.1080/ 15226514.2017.1328392

Berthelot, C., Leyval, C., Foulon, J., Chalot, M., and Blaudez, D. (2016). Plant growth promotion, metabolite production and metal tolerance of dark septate endophytes isolated from metal-polluted poplar phytomanagement sites. FEMS Microbiol. Ecol. 92:fiw144. doi: 10.1093/femsec/fiw144

Cakmak, I., and Marschner, H. (1992). Magnesium deficiency and high light Intensity enhance activities of superoxide dismutase, ascorbate peroxidase, and glutathione reductase in bean leaves. Plant Physiol. 98, 1222-1227. doi: 10.1104/ pp.98.4.1222

Caldwell, B. A., Jumpponen, A., and Trappe, J. M. (2000). Utilization of major detrital substrates by dark-septate, root endophytes. Mycologia 92, 230-232. doi: $10.2307 / 3761555$

Della Monica, I. F., Saparrat, M. C. N., Godeas, A. M., and Scervino, J. M. (2015). The co-existence between DSE and AMF symbionts affects plant P pools through P mineralization and solubilization processes. Fungal Ecol. 17, 10-17. doi: 10.1016/j.funeco.2015.04.004

Deng, J., Ding, G., Gao, G., Wu, B., Zhang, Y., Qin, S., et al. (2015). The sap flow dynamics and response of Hedysarum scoparium to environmental factors in semiarid northwestern China. PLoS One 10:e0131683. doi: 10.1371/journal. pone. 0131683

Elavarthi, S., and Martin, B. (2010). "Spectrophotometric assays for antioxidant enzymes in plants," in Plant Stress Tolerance: Methods and Protocols, ed. R. Sunkar (Totowa, NJ: Humana Press), 273-280.

Fan, B., Zhang, A., Yang, Y., Ma, Q., Li, X., and Zhao, C. (2016). Long-term effects of xerophytic shrub Haloxylon ammodendron plantations on soil properties and vegetation dynamics in Northwest China. PLoS One 11:e0168000. doi: 10.1371/journal.pone. 0168000

Gong, C., Wang, J., Hu, C., Wang, J., Ning, P., and Bai, J. (2015). Interactive response of photosynthetic characteristics in Haloxylon ammodendron and Hedysarum scoparium exposed to soil water and air vapor pressure deficits. J. Environ. Sci. 34, 184-196. doi: 10.1016/j.jes.2015.03.012

\section{FUNDING}

This study was financially supported by the National Natural Science Foundation of China (Project Nos. 31470533, 31770561, and 31800345).

\section{SUPPLEMENTARY MATERIAL}

The Supplementary Material for this article can be found online at: https://www.frontiersin.org/articles/10.3389/fpls.2019.00903/ full\#supplementary-material

González-Teuber, M., Urzúa, A., Plaza, P., and Bascuñán-Godoy, L. (2018). Effects of root endophytic fungi on response of Chenopodium quinoa to drought stress. Plant Ecol. 219, 231-240. doi: 10.1007/s11258-017-0791-1

González-Teuber, M., Vilo, C., and Bascuñángodoy, L. (2017). Molecular characterization of endophytic fungi associated with the roots of Chenopodium quinoa inhabiting the Atacama Desert. Chile. Genomics Data 11, 109-112. doi: 10.1016/j.gdata.2016.12.015

Hu, X. W., Wang, Y. R., and Wu, Y. P. (2009). Effects of the pericarp on imbibition, seed germination, and seedling establishment in seeds of Hedysarum scoparium Fisch. et Mey. Ecol. Res. 24, 559-564. doi: 10.1007/s11284-008-0524-y

Jin, H. Q., Liu, H. B., Xie, Y. Y., Zhang, Y. G., Xu, Q. Q., Mao, L. J., et al. (2018). Effect of the dark septate endophytic fungus Acrocalymma vagum on heavy metal content in tobacco leaves. Symbiosis 74, 89-95. doi: 10.1007/s13199-0170485-4

Jumpponen, A., and Trappe, J. M. (1998). Dark septate endophytes: a review of facultative biotrophic root-colonizing fungi. New Phytol. 140, 295-310. doi: 10.1046/j.1469-8137.1998.00265.x

Khan, M. M., Islam, E., Irem, S., Akhtar, K., Ashraf, M. Y., Iqbal, J., et al. (2018). $\mathrm{Pb}$-induced phytotoxicity in para grass (Brachiaria mutica) and castorbean (Ricinus communis L.) antioxidant and ultrastructural studies. Chemosphere 200, 257-265. doi: 10.1016/j.chemosphere.2018.02.101

Khastini, R. O., Ohta, H., and Narisawa, K. (2012). The role of a dark septate endophytic fungus, Veronaeopsis simplex Y34, in Fusarium disease suppression in Chinese cabbage. J. Microbiol. 50, 618-624. doi: 10.1007/s12275-012-2105-6

Kivlin, S. N., Emery, S. M., and Rudgers, J. A. (2013). Fungal symbionts alter plant responses to global change. Am. J. Bot. 100, 1445-1457. doi: 10.3732/ajb. 1200558

Knapp, D. G., Kovács, G. M., Zajta, E., Groenewald, J. Z., and Crous, P. W. (2015). Dark septate endophytic pleosporalean genera from semiarid areas. Persoonia 35, 87-100. doi: 10.3767/003158515X687669

Knapp, D. G., Pintye, A., and Kovács, G. M. (2012). The dark side is not fastidiousdark septate endophytic fungi of native and invasive plants of semiarid sandy areas. PLoS One 7:e32570. doi: 10.1371/journal.pone.0032570

Li, B., He, X., He, C., Chen, Y., and Wang, X. (2015). Spatial dynamics of dark septate endophytes and soil factors in the rhizosphere of Ammopiptanthus mongolicus in inner mongolia. China. Symbiosis 65, 75-84. doi: 10.1007/s13199015-0322-6

Li, L., Chen, X., Shi, L., Wang, C., Fu, B., Qiu, T., et al. (2017). A proteome translocation response to complex desert stress environments in perennial Phragmites sympatric ecotypes with contrasting water availability. Front. Plant Sci. 8:511. doi: 10.3389/fpls.2017.00511

Li, T., Liu, M. J., Zhang, X. T., Zhang, H. B., Sha, T., and Zhao, Z. W. (2011). Improved tolerance of maize (Zea mays L.) to heavy metals by colonization of a dark septate endophyte (DSE) Exophiala pisciphila. Sci. Total Environ. 409, 1069-1074. doi: 10.1016/j.scitotenv.2010.12.012

Li, X., He, X., Hou, L., Ren, Y., Wang, S., and Su, F. (2018). Dark septate endophytes isolated from a xerophyte plant promote the growth of Ammopiptanthus mongolicus under drought condition. Sci. Rep. 8:7896. doi: 10.1038/s41598-01826183-0

Likar, M., and Regvar, M. (2013). Isolates of dark septate endophytes reduce metal uptake and improve physiology of Salix caprea L. Plant Soil 370, 593-604. doi: $10.1007 / \mathrm{s} 11104-013-1656-6$ 
Lugo, M. A., Molina, M. G., and Crespo, E. M. (2009). Arbuscular mycorrhizas and dark septate endophytes in bromeliads from South American arid environment. Symbiosis 47, 17-21. doi: 10.1007/s11104-013-1656-6

Lugo, M. A., Reinhart, K. O., Menoyo, E., Crespo, E. M., and Urcelay, C. (2015). Plant functional traits and phylogenetic relatedness explain variation in associations with root fungal endophytes in an extreme arid environment. Mycorrhiza 25, 85-95. doi: 10.1007/s00572-014-0592-5

Mandyam, K., and Jumpponen, A. (2005). Seeking the elusive function of the root-colonising dark septate endophytic fungi. Stud. Mycol. 53, 173-189. doi: $10.3114 /$ sim.53.1.173

Newsham, K. K. (2011). A meta-analysis of plant responses to dark septate root endophytes. New Phytol. 190, 783-793. doi: 10.1111/j.1469-8137.2010.03611.x

Perez-Naranjo, J. C. (2009). Dark Septate and Arbuscular Mycorrhizal Fungal Endophytes in Roots of Prairie Grasses. Ph.D. Dissertation, Saskatoon: University of Saskatchewan.

Phillips, J. M., and Hayman, D. S. (1970). Improved procedures for clearing roots and staining parasitic and vesicular-arbuscular mycorrhizal fungi for rapid assessment of infection. Trans. Br. Mycol. Soc. 55, 158-163. doi: 10.1016/S00071536(70)80110-3

Porras-Alfaro, A., Herrera, J., Sinsabaugh, R. L., Odenbach, K. J., Lowrey, T., and Natvig, D. O. (2008). Novel root fungal consortium associated with a dominant desert grass. Appl. Environ. Microb. 74, 2805-2813. doi: 10.1128/aem.02769-07

Ren, A. Z., Li, X., Han, R., Yin, L. J., Wei, M. Y., and Gao, Y. B. (2011). Benefits of a symbiotic association with endophytic fungi are subject to water and nutrient availability in Achnatherum sibiricum. Plant Soil 346:363. doi: 10.1007/s11104011-0824-9

Saleem, M., Asghar, H. N., Zahir, Z. A., and Shahid, M. (2018). Impact of lead tolerant plant growth promoting rhizobacteria on growth, physiology, antioxidant activities, yield and lead content in sunflower in lead contaminated soil. Chemosphere 195, 606-614. doi: 606-614. 10.1016/j.chemosphere.2017.12.117

Santos, S. G. D., Silva, P. R. A. D., Garcia, A. C., Zilli, J. É, and Berbara, R. L. L. (2017). Dark septate endophyte decreases stress on rice plants. Brazilian. J. Microbiol. 48, 333-341. doi: 10.1016/j.bjm.2016.09.018

Shi, Z., Mickan, B., Feng, G., and Chen, Y. (2015). Arbuscular mycorrhizal fungi improved plant growth and nutrient acquisition of desert ephemeral Plantago minuta under variable soil water conditions. J. Arid. Land. 7, 414-420. doi: 10.1007/s40333-014-0046-0

Su, Y. Z., Zhao, W. Z., Su, P. X., Zhang, Z. H., Wang, T., and Ram, R. (2007). Ecological effects of desertification control and desertified land reclamation in an oasis-desert ecotone in an arid region: a case study in hexi corridor, northwest China. Ecol. Eng. 29, 117-124. doi: 10.1016/j.ecoleng.2005. 10.015

Su, Z. Z., Mao, L. J., Li, N., Feng, X. X., Yuan, Z. L., Wang, L. W., et al. (2013). Evidence for biotrophic lifestyle and biocontrol potential of dark septate endophyte Harpophora oryzae to rice blast disease. PLoS One 8:e61332. doi: 10.1371/journal.pone.0061332

Surono, and Narisawa, K. (2017). The dark septate endophytic fungus Phialocephala fortinii is a potential decomposer of soil organic compounds and a promoter of Asparagus officinalis growth. Fungal Ecol. 28, 1-10. doi: 10.1016/j.funeco.2017.04.001

Tang, Z., An, H., Deng, L., Wang, Y., Zhu, G., and Shangguan, Z. (2016). Effect of desertification on productivity in a desert steppe. Sci. Rep. 6:27839. doi: 10.1038/srep27839

Vergara, C., Araujo, K. E. C., Urquiaga, S., Santa-Catarina, C., Schultz, N., Araujo, E. D. S., et al. (2018). Dark septate endophytic fungi increase green manure$\mathrm{N}-15$ recovery efficiency, $\mathrm{N}$ contents, and micronutrients in rice grains. Front. Plant Sci. 9:613. doi: 10.3389/fpls.2018.00613

Wang, J. L., Li, T., Liu, G. Y., Smith, J. M., and Zhao, Z. W. (2016). Unraveling the role of dark septate endophyte (DSE) colonizing maize (Zea mays) under cadmium stress: physiological, cytological and genic aspects. Sci. Rep. 6:22028. doi: $10.1038 /$ srep 22028

Wang, X. P., Zhang, Y. F., Hu, R., Pan, Y. X., and Berndtsson, R. (2012). Canopy storage capacity of xerophytic shrubs in Northwestern China. J. Hydrol. 45, 152-159. doi: 10.1016/j.jhydrol.2012.06.003

Wilcox, H. E., and Wang, C. J. K. (1987). Ectomycorrhizal and ectendomycorrhizal associations of Phialophorafinlandia with Pinus resinosa, Picear ubens, and Betula alleghaniensis. Can. J. Res. 17, 976-990. doi: 10.1139/x87-152

Wu, L. Q., Lv, Y. L., Meng, Z. X., Chen, J., and Guo, S. X. (2010). The promoting role of an isolate of dark-septate fungus on its host plant Saussurea involucrata Kar. et Kir. Mycorrhiza 20, 127-135. doi: 10.1007/s00572-009-0268-8

Xie, L. (2017). Species Diversity and Salt Tolerance of DSE in The Roots of Hedysarum Scoparium Fisch. et Mey. in Northwest China. Ph.D. Dissertation, Baoding: Hebei University.

Xie, L., He, X., Wang, K., Hou, L., and Sun, Q. (2017). Spatial dynamics of dark septate endophytes in the roots and rhizospheres of Hedysarum scoparium in northwest China and the influence of edaphic variables. Fungal Ecol. 26, 135-143. doi: 10.1016/j.funeco.2017.01.007

Xie, W., Hao, Z., Zhou, X., Jiang, X., Xu, L., Wu, S., et al. (2018). Arbuscular mycorrhiza facilitates the accumulation of glycyrrhizin and liquiritin in Glycyrrhiza uralensis under drought stress. Mycorrhiza 28, 285-300. doi: 10. 1007/s00572-018-0827-y

Zhang, Q. M., Gong, M. G., Yuan, J. F., Hou, Y., Zhang, H. M., Wang, Y., et al. (2017). Dark septate endophyte improves drought tolerance in Sorghum. Int. J. Agric. Biol. 19, 53-60. doi: 10.17957/ijab/15.0241

Zhu, Z. D., and Chen, G. T. (1994). Land Sandy Desertification in China. Beijing: Science Press.

Conflict of Interest Statement: The authors declare that the research was conducted in the absence of any commercial or financial relationships that could be construed as a potential conflict of interest.

Copyright (c) $2019 \mathrm{Li}, \mathrm{He}, \mathrm{Zhou}, \mathrm{Hou}$ and Zuo. This is an open-access article distributed under the terms of the Creative Commons Attribution License (CC BY). The use, distribution or reproduction in other forums is permitted, provided the original author(s) and the copyright owner(s) are credited and that the original publication in this journal is cited, in accordance with accepted academic practice. No use, distribution or reproduction is permitted which does not comply with these terms. 